\title{
How do hospitalization patterns of home hemodialysis patients compare with a reasonably well dialysis patient cohort?
}

This article was published in the following Dove Press journal: International Journal of Nephrology and Renovascular Disease 30 May 2014

Number of times this article has been viewed

\section{Edward Zimbudzi ${ }^{1,2}$ \\ Reggie Samlero'}

'Department of Nephrology, Monash Health, Monash Medical Centre, Clayton, Melbourne, VIC, Australia; ${ }^{2}$ School of Nursing and Midwifery, Faculty of Health Sciences, Latrobe University, Bundoora, VIC, Australia

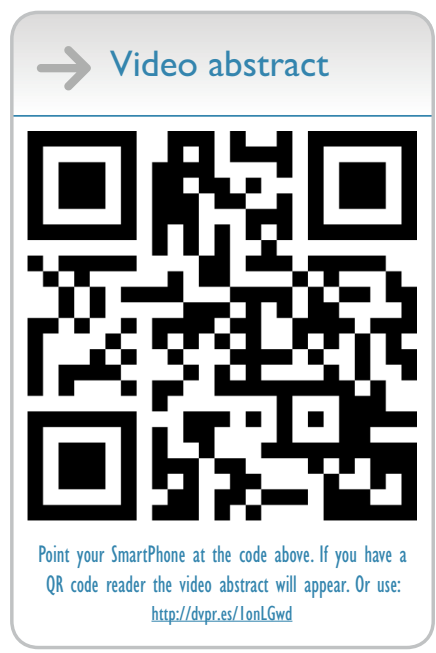

Correspondence: Edward Zimbudzi Department of Nephrology, Monash Health, Monash Medical Centre, Clayton, VIC 3168, Australia

$\mathrm{Tel}+6 \mathrm{I} 395943618$

Fax +6I 395946907

Email edward.zimbudzi@southernhealth. org.au
Background: The home hemodialysis (HHD) treatment option has been associated with improved patient outcomes compared to in-center hemodialysis (ICHD) programs. What is not quite clear is the influence of patient selection bias on the perceived benefits of HHD. The purpose of this study was to explore the potential benefits of HHD by comparing the admission patterns of HHD patients with a control group from a reasonably well dialysis patient cohort, which in this case were satellite hemodialysis patients on a Category 1 transplant waiting list (Cat1 SHD).

Methods: A single center retrospective randomized cohort study of HHD and Cat1 SHD patients who were on these two treatment modalities from August 2012 to August 2013 was performed to obtain a sample of 25 patients for each group.

Results: The mean length of stay in hospital was 5.9 days for HHD patients and 6.7 days for Cat1 SHD group $(P=0.8)$. Eighteen admissions were observed for both groups ( 0.72 admissions/ patient-year; $P=0.5$ ). HHD patients spent 71 days and Cat1 SHD patients spent 85 days in hospital (2.8 and 3.4 days/patient-year respectively; $P<0.005$ ). The mean serum potassium level for HHD patients was $4.1(3.1-6.5) \mathrm{mEq} / \mathrm{L}$ versus $5.0(3.7-6.1) \mathrm{mEq} / \mathrm{L}$ for Cat1 SHD patients $(P=0.001)$ and the mean phosphate level was $1.1(0.56-2.38) \mathrm{mg} / \mathrm{dL}$ and $1.5(0.43-3.2) \mathrm{mg} / \mathrm{dL}$ ( $P=0.02$ ) for the respective groups.

Conclusion: This study confirms the superiority of the HHD treatment option in improving patient outcomes. Admission patterns of HHD patients fared very well against a control group which consisted of reasonably well dialysis patients.

Keywords: home hemodialysis, satellite hemodialysis, hospitalization patterns, length of stay

\section{Background}

Hospitalizations have been shown to be a major indicator of morbidity for patients with end-stage renal disease on hemodialysis. ${ }^{1}$ Daratha et $\mathrm{al}^{2}$ reveal that risks of subsequent hospitalizations are substantially increased in patients with kidney disease and as a result of this, patients with renal disease should be a focus of efforts to reduce hospitalizations. Chief among these risks of hospitalization are mortality and further debilitation. ${ }^{3}$ Another major downside of hospitalizations among this patient group is the financial burden associated with inpatient care. Caring for hospitalized hemodialysis patients has been identified as one of the costliest elements of their treatment. ${ }^{4}$ Given this setting, any intervention that would reduce hospitalization among hemodialysis patients would potentially bring in huge financial benefits to health institutions, and simultaneously, patient outcomes may be improved substantially.

Studies have critically examined the roles of different methods of dialysis in an attempt to determine whether any particular method would be associated with reduced 
hospitalization rates. Kumar et al, ${ }^{5}$ in their comparative study of hospitalization rates in daily home hemodialysis (HHD) versus peritoneal dialysis patients in the US, concluded that patients treated with daily HHD spend fewer days in hospital than peritoneal dialysis patients. Comparison of hospitalization rates in patients being treated with different dialysis methods is quite a challenging task technically. This is because of the differences in the severity of various comorbidities associated with patients on dialysis.

The HHD method has generated a lot of interest with regards to its contribution in reducing hospitalizations. However, there are very limited randomized controlled trials to date which have compared the HHD modality with other hemodialysis methods. Reported survival benefits of HHD as compared with in-center hemodialysis (ICHD) from uncontrolled studies have been attributed largely to patient selection. ${ }^{6}$ Patients who are deemed fitter and with less comorbidities are practically preferred candidates for HHD. As a result of selection criteria, the ICHD program is left with patients who are more likely to be hospitalized.

Our study sought to investigate the hospitalization patterns of HHD patients. Having known of the impact of selection criteria on HHD candidates, in our study we chose a control group of patients we thought compared well with HHD patients from a demographic and comorbidity point of view. We settled for patients on a category 1 transplant list dialyzing in satellite units. These patients are generally healthier and younger and therefore mimic the HHD patient group in a lot of ways.

\section{Methods}

This study was conducted from August 2012 to August 2013 at a major referral metropolitan hospital (Monash Medical Centre, Melbourne, Australia). This public hospital has over 400 patients on dialysis with HHD contributing about $20 \%$ of these patients. Most of the patients are managed by institutionalized hemodialysis which is offered at urban and regional satellite units affiliated to the hospital. The hospital's transplant unit manages the transplant waiting list for all categories including the pancreas-kidney transplant, of which this hospital is one of the two Australian hospitals which perform this procedure. The HHD training unit is strategically located 20 minutes away from the main hospital and has its clientele scattered around suburban and regional areas. HHD candidates normally would have dialyzed in the in-center unit or in satellite units before they commence hemodialysis training. However, on rare occasions, the home dialysis training unit has started hemodialysis on new patients. More than $75 \%$ of HHD patients dialyze for 8 hours every second day, while the majority of the satellite patients dialyze for 5 hours, three times a week.

A retrospective cohort study of HHD patients and satellite hemodialysis patients on a Category 1 transplant waiting list (Cat1 SHD), who were on these two treatment modalities was performed by simple randomization to obtain a sample of 25 patients for each group. Patients were randomly selected from the HHD list and from the Cat1 SHD by a staff member who was not involved in the project. The medical records and blood results of the selected patients were then accessed electronically and examined for information on their admission patterns. Information gathered was organized into demographic data, admission episodes, length of stay (LOS) in the hospital, primary cause of renal disease, diagnosis on admission, and laboratory values. We utilized descriptive statistics to describe the basic features of the study data and an alpha level of 0.05 was used for all statistical tests.

\section{Results}

The patient characteristics are shown in Table 1. More men were on HHD $(\mathrm{N}=16)$ and Cat1 SHD $(\mathrm{N}=15)$. There was no difference between the mean ages of these two groups of patients $(P=0.08)$ and the time they had been on dialysis $(P=0.3)$. The mean LOS in hospital was 5.9 days for HHD patients and 6.7 days for Cat1 SHD group. There was no difference between the mean LOS of these two patient groups $(P=0.8)$. Eighteen admissions were observed for both groups during the study period ( 0.72 admissions/patient-year; $P=0.5)$. HHD patients spent 71 days and Cat1 SHD patients spent 85 days in hospital (2.8 and 3.4 days/patient-year respectively; $P<0.005)$.

More than $50 \%$ of cases in both groups had renal failure caused by diabetes, IGA nephropathy and reflux (see Table 2). Dialysis-related surgical procedures contributed 52\% and $8.5 \%$ of in patient days for Cat1 SHD and HHD patients respectively (see Table 3 ). The absolute risk for an admission

Table I Patient characteristics

\begin{tabular}{lll}
\hline Patient characteristics & HHD & Cat I SHD \\
\hline Male/female & $\mathrm{N}=16 / 9$ & $\mathrm{~N}=15 / 10$ \\
Mean age $^{\mathrm{a}}$ & $\mathrm{M}=53.6(35-76)$ & $\mathrm{M}=47.4(25-69)$ \\
Patients admitted & $\mathrm{N}=18$ & $\mathrm{~N}=18$ \\
In patient days & $7 \mathrm{I}$ & 85 \\
Length of stay (days) $^{\mathrm{a}}$ & $\mathrm{M}=5.9(\mathrm{I}-13)$ & $\mathrm{M}=6.7(\mathrm{I}-22)$ \\
Number of years on dialysis $^{\mathrm{a}}$ & $\mathrm{M}=4.6(\mathrm{I}-18)$ & $\mathrm{M}=3.4(\mathrm{I}-\mathrm{I6})$ \\
\hline
\end{tabular}

Note: a $P>0.05$ suggesting no difference between the two means.

Abbreviations: HHD, home hemodialysis patients; Cat I SHD, satellite hemodialysis patients on Category I transplant list; N, number of patients; $M$, mean value. 
Table 2 Primary cause of ESRF

\begin{tabular}{lll}
\hline Primary cause of ESRF & $\begin{array}{l}\text { HHD } \\
(\mathbf{N = 2 5 )}\end{array}$ & $\begin{array}{l}\text { Cat I SHD } \\
(\mathbf{N = 2 5 )}\end{array}$ \\
\hline Diabetes & 4 & 7 \\
Glomerulonephritis & $\mathrm{I}$ & 3 \\
Focal segmental glomerulosclerosis & 2 & $\mathrm{I}$ \\
Adult polycystic kidney disease & 2 & 3 \\
lgA nephropathy & 5 & 2 \\
Reflux & 4 & 4 \\
Goodpastures Syndrome & 2 & 0 \\
Vasculitis & 3 & $\mathrm{I}$ \\
Hypertension & 2 & 0 \\
Other (congenital small kidneys, & 0 & 4 \\
alports, nephrosclerosis) & & \\
\hline
\end{tabular}

Abbreviations: ESRF, end-stage renal failure; HHD, home hemodialysis patients; Cat I SHD, satellite hemodialysis patients on Category I transplant list; N, number of patients; IgA, Immunoglobulin A.

due to a vascular event for Cat 1 SHD patients was 0.28 and 0.04 for HHD patients with an absolute risk excess of 0.24 .

The odds ratio of an admission due to a vascular event was 0.39 for Cat 1 SHD patients and 0.04 for HHD patients.

On the other hand, LOS associated with non-dialysis related surgical procedures was more common among HHD patients $(32 \%)$. There were two Cat1 SHD patients who were admitted for treatment of electrolyte imbalances such as hyperkalemia, and their LOS was 15 days. It is important to note that there was one HHD patient who had unstable diabetes with a LOS of 13 days.

Laboratory values for both groups of patients are listed in Table 4. The mean serum potassium level for HHD patients was $4.1(3.1-6.5) \mathrm{mEq} / \mathrm{L}$ versus $5.0(3.7-6.1) \mathrm{mEq} / \mathrm{L}$ for Cat1 SHD patients $(P=0.001)$ and the mean phosphate

Table 3 Diagnosis on admission and associated length of stay

\begin{tabular}{|c|c|c|c|c|}
\hline Admission diagnosis & $\begin{array}{l}\text { HHD } \\
(\mathbf{N})\end{array}$ & $\begin{array}{l}\text { LOS } \\
\text { (days) }\end{array}$ & $\begin{array}{l}\text { Catl SHD } \\
\text { (N) }\end{array}$ & $\begin{array}{l}\text { LOS } \\
\text { (days) }\end{array}$ \\
\hline $\begin{array}{l}\text { Infection: osteomyelitis, } \\
\text { pneumonia, viral infection }\end{array}$ & 2 & 8 & 3 & 12 \\
\hline Surgical: dialysis access & I & 6 & 7 & 44 \\
\hline $\begin{array}{l}\text { Surgical-other: inguinal } \\
\text { hernia repair }\end{array}$ & 8 & 23 & 2 & 2 \\
\hline $\begin{array}{l}\text { Cardiac: NSTEMI, } \\
\text { hypotension }\end{array}$ & 4 & 14 & 3 & 5 \\
\hline $\begin{array}{l}\text { Electrolyte imbalances: } \\
\text { hyperkalemia }\end{array}$ & 0 & 0 & 2 & 15 \\
\hline $\begin{array}{l}\text { Endocrinology: unstable } \\
\text { diabetes }\end{array}$ & I & 13 & 0 & 0 \\
\hline $\begin{array}{l}\text { Gastrointestinal: nausea } \\
\text { and vomiting, constipation, } \\
\text { decreased oral intake }\end{array}$ & I & 2 & 2 & 7 \\
\hline Neurological: stroke & I & 7 & 0 & 0 \\
\hline
\end{tabular}

Abbreviations: NSTEMI, non-ST segment elevation myocardial infarction; HHD, home hemodialysis patients; CatI SHD, satellite hemodialysis patients on Category I transplant list; N, number of patients in that category; LOS, length of stay.
Table 4 Recent laboratory values

\begin{tabular}{|c|c|c|c|}
\hline Laboratory test & $\begin{array}{l}\text { HHD, mean } \\
\text { (range) }\end{array}$ & $\begin{array}{l}\text { Catl SHD, } \\
\text { mean (range) }\end{array}$ & $P$-value \\
\hline Hemoglobin (g/dL) & II 0.8 (87-135) & $109.2(91-139)$ & ${ }^{\mathrm{a}} 0.63$ \\
\hline Creatinine $(\mathrm{mg} / \mathrm{dL})$ & $445.1(191-902)$ & $768.5(290-1,368)$ & 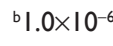 \\
\hline Potassium (mEq/L) & $4.1(3.1-6.5)$ & $5.0(3.7-6.1)$ & ${ }^{\mathrm{b}} 0.001$ \\
\hline Phosphate (mg/dL) & I.I (0.56-2.38) & I.5 (0.43-3.2) & ${ }^{\mathrm{b}} 0.02$ \\
\hline Albumin (g/dL) & $36.0(28-42)$ & $36.4(31-40)$ & ${ }^{\mathrm{a}} 0.75$ \\
\hline
\end{tabular}

Notes: $P$-values: a $P>0.05$ suggesting no difference between the two means; ${ }^{\mathrm{b} P}<0.05$ suggesting a difference between the two means.

Abbreviations: HHD, home hemodialysis patients; CatI SHD, satellite hemodialysis patients on Category I transplant list.

level was $1.1(0.56-2.38) \mathrm{mg} / \mathrm{dL}$ and $1.5(0.43-3.2) \mathrm{mg} / \mathrm{dL}$ ( $P=0.02$ ) for the respective groups. No notable differences were found between the two groups' hemoglobin, creatinine and albumin levels; $P$-values were $0.63,1.0 \times 10^{-6}$, and 0.75 , respectively.

\section{Discussion}

We compared the admission patterns of HHD patients and a Cat1 SHD cohort to determine if the HHD patients performed better. Several studies on the HHD patient cohort have demonstrated a varied number of positive findings, such as survival advantage $\mathrm{e}^{7-10}$ which has been explained partly by selection bias. We were cognizant of the fact that our HHD group could have been made up of patients who were physically and clinically stable and that is why, of all hemodialysis patient groups, we utilized the Cat1 SHD patients, who in most cases tend to have less comorbidities.

The demographic patterns of our study patients did not have major notable variations. There were more men in each treatment modality. There was also a six-year mean age difference between the two groups with HHD patients tending to be a bit older, but this was not a statistically significant finding. Despite the homogeneity of the demographics of these two groups, there were some differences in their admission patterns which were not, however, statistically backed up. There was a 0.8 of a day difference in LOS and 14 day difference in the total number of days spent in hospital all in favor of the HHD group. Our prediction is that if our study had randomly selected patients from an ICHD cohort, then the above results would have been further skewed in favor of the HHD group.

Previous studies have identified maintenance hemodialysis as a risk factor for prolonged hospitalization regardless of the primary reason for admission, and it has been shown that such patients require admission more frequently than the general population, particularly within 100 days before and after initiation of the first dialysis treatment. ${ }^{10} \mathrm{To}$ reduce bias, especially with some of our Cat1 SHD patients 
who would have been on dialysis for a period of 100 days or less, we excluded all patients who had less than 1 year on dialysis.

Our study supports the findings of a systematic review of the effectiveness of home versus hospital or satellite unit hemodialysis for people with end-stage renal failure by Mowatt et al, ${ }^{11}$ who concluded that patients receiving HHD are more likely to work, have lower mortality rates, experience less hospitalization, and have less dialysis-related complications than satellite or hospital-based hemodialysis patients. Looking at dialysis-related complications in our study, and using dialysis access as an example, there was only one HHD patient who was admitted primarily for dialysis access interventions compared to seven Cat1 SHD patients. Woods et $\mathrm{al}^{12}$ also identified more vascular problems in the ICHD patients compared to the HHD patients. A possible explanation could be that HHD candidates are referred to the home dialysis unit with an already well-functioning vascular access that would have been used several times. On the other hand, the Cat1 SHD group may potentially have vascular access which is maturing and not well established. During the study period, it is worth noting that none of the HHD patients was admitted with hyperkalemia, and only one had nausea and vomiting, which are both signs of suboptimal dialysis. This may explain why the HHD patient group had fewer dialysis-related admissions compared to the control group.

This study was limited in several ways. The small number of patients which we used could have led to a type 2 statistical error. In addition to this, admissions which occurred only at the patient's parent hospital were considered for this study. There could have been some patients who were admitted elsewhere during the study period. However, we do not believe that these admissions would have affected our findings significantly since our dialysis patients are encouraged to present to their parent hospital unless the hospital is on bypass. The HHD unit list we used was also based on patients whose parent hospital was our hospital. The HHD unit has trained some patients belonging to other hospitals who were privately referred by their nephrologists due to geographical convenience and such patients were excluded from our study. We attempted to minimize selection bias by randomly selecting the 50 patients. As experienced by other studies, ${ }^{13,14}$ our retrospective study was severely limited by unmeasured confounders.
In conclusion, our study findings have demonstrated that the strength of the HHD program lies in its equivalence with or superiority to the best possible ICHD candidates with regards to hospital admissions. We therefore hypothesize that the more patients we have on the HHD treatment modality, the less the hospital admissions. The overall results are improved patient outcomes and a reduced financial burden for health institutions.

\section{Disclosure}

The authors report no conflicts of interest in this work.

\section{References}

1. Adeniyi M, Kassam H, Agaba EI, et al. Hospitalizations in patients treated sequentially by chronic hemodialysis and continuous peritoneal dialysis. Adv Perit Dial. 2009;25:72-75.

2. Daratha KB, Short RA, Corbett CF, et al. Risks of subsequent hospitalization and death in patients with kidney disease. Clin J Am Soc Nephrol. 2012;7(3):409-416.

3. Mailloux LU, Kapikian N, Napolitano B, et al. Home hemodialysis: patient outcomes during a 24-year period of time from 1970 through 1993. Adv Ren Replace Ther. 1996;3(2):112-119.

4. Lee H, Manns B, Taub K, et al. Cost analysis of ongoing care of patients with end-stage renal disease: the impact of dialysis modality and dialysis access. Am J Kidney Dis. 2002;40(3):611-622.

5. Kumar VA, Ledezma ML, Idroos ML, Burchette RJ, Rasgon SA. Hospitalization rates in daily home hemodialysis versus peritoneal dialysis patients in the United States. Am J Kidney Dis. 2008;52(4):737-744.

6. Saner E, Nitsch D, Descoeudres C, Frey FJ, Uehlinger DE. Outcome of home haemodialysis: a case-cohort study. Nephrol Dial Transplant. 2005;20(3):604-610.

7. Delano BG. Home hemodialysis offers excellent survival. Adv Ren Replace Ther. 1996;3(2):106-111.

8. Covic A, Goldsmith DJ, Venning MC, Ackrill P. Long-hours home haemodialysis - the best renal replacement method? QJM. 1999;92(5): 251-260.

9. McGregor DO, Buttimore AL, Lynn KL. Home hemodialysis: excellent survival at less cost, but still underutilized. Kidney Int. 2000;57(6):2654-2655.

10. Quinn MP, Cardwell CR, Rainey R, et al. Patterns of hospitalisation before and following initiation of haemodialysis: a 5 year single centre study. Postgrad Med J. 2011;87(1028):389-393.

11. Mowatt G, Vale L, MacLeod A. Systematic review of the effectiveness of home versus hospital or satellite unit hemodialysis for people with end-stage renal failure. Int J Technol Assess Health Care. 2004;20(3):258-268.

12. Woods JD, Port FK, Stannard D, Blagg CR, Held PJ. Comparison of mortality with home hemodialysis and center hemodialysis: a national study. Kidney Int. 1996;49(5):1464-1470.

13. MacGregor MS. Outcomes on home hemodialysis: registry challenges. NDT Plus. 2011;4(Suppl3):iii32-iii35.

14. Weinhandl ED, Liu J, Gilbertson DT, Arneson TJ, Collins AJ. Survival in daily home hemodialysis and matched thrice-weekly in-centre hemodialysis patients. J Am Soc Nephrol. 2012;23:895-904. 
International Journal of Nephrology and Renovascular Disease

\section{Publish your work in this journal}

The International Journal of Nephrology and Renovascular Disease is an international, peer-reviewed open-access journal focusing on the pathophysiology of the kidney and vascular supply. Epidemiology, screening, diagnosis, and treatment interventions are covered as well as basic science, biochemical and immunological studies. The journal welcomes

original research, clinical studies, reviews \& evaluations, expert opinion and commentary, case reports and extended reports. The manuscript management system is completely online and includes a very quick and fair peerreview system, which is all easy to use. Visit http://www.dovepress.com/ testimonials.php to read real quotes from published authors.

Submit your manuscript here: http://www.dovepress.com/international-journal-of-nephrology-and-renovascular-disease-journal 